\title{
Visual Pathway Glioma
}

National Cancer Institute

\section{Source}

National Cancer Institute. Visual Pathway Glioma. NCI Thesaurus. Code C8567.

A glioma that affects the optic tract. This condition can be seen in association with neurofibromatosis 1 . It is most commonly seen in the pediatric age group. 